\title{
PERBEDAAN EFEKTIVITAS PENDIDIKAN KESEHATAN PEMERIKSAAN PAYUDARA SENDIRI (SADARI) DENGAN MENGGUNAKAN MEDIA LEAFLET DAN MEDIA AUDIO VISUAL PADA REMAJA PUTRI DI SMK NU UNGARAN
}

\author{
Arida Wahyu Endah Pratiwi ${ }^{1}$, Luvi Dian Afriyani ${ }^{2}$, Adil Zulkarnain ${ }^{3}$ \\ Program Studi DIV Kebidanan, Universitas Ngudi Waluyo, Ungaran \\ Email : aridawahyu.endahpratiwi@gmail.com
}

\begin{abstract}
ABSTRAK
Di Indonesia kanker payudara merupakan kanker nomor dua setelah kanker serviks, presentase kanker payudara di Indonesia yaitu $(1,4 \%)$ sekitar 347.792 orang sedangkan presentase di Jawa Tengah $(0,7 \%)$ sekitar 11.511 orang. Salah satu faktor tingginya angka kejadian kanker payudara adalah kurangnya edukasi dan pemeriksaan kanker payudara sejak dini dalam mendeteksi dan menangani kanker payudara. Pendidikan kesehatan dengan media audio visual dan media leaflet diharapkan dapat meningkatkan pengetahuan siswi tentang SADARI. Untuk mengetahui efektifitas pendidikan kesehatan tentang SADARI dengan menggunakan media audio visual dan leaflet pada remaja putri di SMK NU Ungaran Tahun 2019. Jenis penelitian yang digunakan pada penelitian ini adalah quasi experiment. Penelitian menggunakan desain penelitian berbentuk counterbalanced design. Tehnik analisis data yang digunakan adalah uji $t$ test. Berdasarkan uji t independen, didapatkan nilai t hitung sebesar 2,090 dengan pvalue 0,040 dan $p$-value $0,040<\alpha(0,05)$ yaitu media audio visual lebih efektif untuk memberikan pendidikan kesehatan terhadap pengetahuan remaja putri. Penggunaan media audio visual lebih efektif untuk memberikan pendidikan kesehatan pada remaja putri.
\end{abstract}

Kata Kunci : Pendidikan Kesehatan, media Audio Visual, media Leaflet, SADARI, remaja putri

\begin{abstract}
The Difference of the Effectiveness of Health Education in Own Breast SelfExamination (BSE) Using Leaflet Media and Audio Visual Media on Female Studens at NU Ungaran Vocational School

Cancer is one of the main causes of death and the type of cancer that is more common in women is breast cancer. In Indonesia, breast cancer is the number two cancer after cervical cancerwhile the percentage of breast cancer in Indonesia is (0.7\%). One factor of the high case of breast cancer is the lack of education and examination of breast cancer early in detecting and treating breast cancer. One way to provide information about breast self - examination(BSE) to students is by providing health education with audio visual media and leaflet media that are expected to increase student knowledge about breast self - examination(BSE). To determine the effectiveness of health education about breast self - examination breast self - examination(BSE) by using audio visual media and leaflets in young women in Ungaran NU Vocational School in 2019. The type of research used in this study is quasi experiment. The research uses a
\end{abstract}


counterbalanced design research design. The data analysis technique used was the $t$ test. Based on the independent t test, the value of t count is 2.090 with p-value 0.040 and $p$-value $0.040<(0.05) \alpha$ that is audio visual media is more effective in providing health education to the knowledge of young women. Better use of audio-visual media is recommended to provide health education to female students.

Keywords : health education, audio visual media, leaflet media, SADARI, girls teenager.

\section{PENDAHULUAN}

Penyakit kanker merupakan salah satu penyebab kematian utama di seluruh dunia. Kanker menjadi penyebab kematian sekitar 8,2 juta orang pada tahun 2012. Kanker paru, hati, perut, kolorektal dan kanker payudara adalah penyebab terbesar kematian akibat kanker setiap tahunnya. Estimasi presentase kasus baru akibat kanker pada penduduk dunia tahun 2012 untuk kasus baru tertinggi adalah kanker payudara yaitu $43,1 \%$ diikuti kanker prostat sebesar $30,7 \%$ dan kanker paru 23,1\%. Estimasi presentase kematian akibat kanker pada penduduk dunia tahun 2012 peringkat pertama adalah kanker paru yaitu $19,7 \%$ dan dibawahnya kanker payudara yaitu 12,9\% (Kemenkes RI, 2015).

Menurut World Health Organization (WHO) melaporkan kanker payudara merupakan kanker yang diderita oleh perempuan baik di Negara maju maupun di Negara berkembang. Jumlah kasus kanker payudara di dunia (2013) mencapai 6,3 juta dan menduduki peringkat kedua jenis kanker yang paling banyak di derita wanita (WHO, 2013). Sedangkan di Indonesia kanker payudara merupakan kanker nomor dua setelah kanker serviks. Berdasarkan data Riset Kesehatan Dasar tahun 2013, prevalensi kanker payudara di Indonesia mencapai 1,4 per 1.000 penduduk atau sekitar 347.000 orang serta merupakan penyebab kematian nomor $7(5,7 \%)$ dari seluruh penyebab kematian. Pada Provinsi Jawa Tengah jumlah kanker payudara $(0,7 \%)$ yaitu 11.511 orang sedangkan jumlah kanker serviks (1,2\%) yaitu 19.734 orang, dan kanker prostat $(0,2 \%) 3,248$ orang (Kemenkes RI,2015).

Kanker payudara adalah kanker paling umum kedua di dunia dan merupakan kanker yang paling sering diantara perempuan dengan perkiraan 1,67 juta kasus kanker baru yang di diagnosis pada tahun 2012 (25\% dari semua kanker). Kasus kanker payudara lebih banyak terjadi di daerah kurang berkembang (883.000 kasus) dibandingkan dengan daerah yang lebih maju (794.000 kasus). Tingkat Incidence Rate (IR) bervariasi hampir empat kali lipat diseluruh wilayah dunia, mulai dari 27 kasus per 100.000 di Afrika Tengah dan Asia Timur sampai 92 kasus per 100.000 di Amerika Utara (Kemenkes RI, 2016).

Kanker masih menempati urutan pertama kasus baru dan kematian akibat kanker yaitu sebesar 4,9 \%. Pada kuesioner Riset Kesehatan Dasar (Riskesdas) yang dilaksanakan oleh Badan Pemelitian dan Pengembangan Kesehatan, Kementerian Kesehatan RI tahun tahun 2018, salah satu pertanyaan adalah penduduk pernah di diagnosis oleh dokter. Berdasarkan wawancara tersebut, didapatkan prevalensi penderita kanker pada penduduk semua umur di Indonesia sebesar 1,8\%. Prevalensi kenker tertinggi berada pada Provinsi DI.Yogyakarta, yaitu sebesar 4,9\% jauh lebih tinggi dibandingkan dengan angka nasional. Prevalensi tertinggi berikutnya berada pada 
Provinsi Sumatra Barat dan Gorontalo yaitu sebesar 2,1\% dan 2,0\% (Riskesdas , 2018).

SADARI atau pemeriksaan payudara sendiri (Breast SelfExamination / BSE) adalah pilihan cara pencegahan kanker payudara yang baik dilakukan, khususnya mulai usia 20-an. Wanita harus mengetahui manfaat dan keterbatasn SADARI dan harus segera menceritakan setiap perubahan payudara yang terjadi kepada dokter ketika dugaan kanker payudara muncul. SADARI rutin memainkan peran besar dalam menemukan benjolan kanker payudara dibandingkan dengan menemukan benjolan tersebut secara kebetulan. Banyak wanita merasa sangat nyaman melakukan SADARI secara teratur setiap bulan setelah masa menstruasi selesai. Selain itu, cara ini juga nyaman karena dilakukan sendiri dirumah kapan saja, saat mandi atau berpakaian. (Astrid, 2015).

Salah satu upaya untuk meningkatkan pengetahuan dan sikap remaja putri untuk melakukan SADARI adalah melalui penyuluhan dengan pelatihan SADARI. Penyuluhan kesehatan adalah suatu kegiatan promosi kesehatan berupa pemberian informasi atau pesan kesehatan untuk memberikan atau meningkatkan pengetahuan dan sikap tentang kesehatan agar memudahkan dalam terjadinya perilaku sehat. (Notoatmodjo, 2012).

Pengetahuan dapat bertambah atau meningkat dengan adanya informasi dengan menggunakan berbagai macam media yaitu ada media cetak dan media elektronik. Adapun media cetak itu antara lain : poster, leaflet, brosur, majalah, surat kabar, stiker dan pamflet, sedangkan media elektronik misalnya : televisi, radio dan tape recorder, vcd, video. Leaflet merupakan salah satu alat peraga yang disusun berdasarkan prinsip bahwa pengetahuan manusia diterima atau ditangkap melalui panca indra. Leaflet yang baik adalah menggunakan bahasa yang sederhana, mudah dimengerti oleh pembacanya, judul yang digunakan menarik untuk dibaca serta dikombinasikan antara tulisan dan gambar, serta materinya sesuai dengan target yang dituju. Leaflet dapat tersebar luas dan merupakan salah satu cara yang berguna untuk menyampaikan informasi kepada para wanita dan keluarganya atau mendukung informasi yang mereka terima ( Yulianti D, 2011).

Penyuluhan kesehatan dengan menggunakan media audio visual merupakan jenis media yang selain mengandung unsur suara juga mengandung unsur gambar yang dapat dilihat, seperti rekaman video, berbagai ukuran film, slide suara dan lain sebagainya. Kemampuan media audio visual ini dianggap lebih baik dan lebih menarik, sebab mengandung kedua unsur, yaitu didengar dan dilihat. Melalui media audio visual diharapkan promosi kesehatan akan semakin efektif untuk meningkatkan pengetahuan siswi karena melalui media ini siswi akan dipaparkan secara spesifik tentang SADARI, yaitu meliputi pengertian, manfaat, tujuan, waktu dan metode yang baik dan benar untuk melakukan SADARI (Notoatmodjo, 2010)

\section{BAHAN DAN METODE}

Jenis penelitian ini adalah quasi experiment, rancangan penelitian ini mengobservasi sebanyak dua kali yaitu sebelum dan sesudah, peneliti membagi responden menjadi dua kelompok yaitu kelompok yang diberi media leaflet sebagai kelompok perlakuan pertama dan kelompok yang diberi media audiovisual sebagai kelompok perlakuan kedua. Peneliti menggunakan desain penelitian berbentuk counterbalanced design. Peneliti merancang penelitian yang 
membandingkan hasil pengukuran pengetahuan tantang SADARI pada kelompok I dengan kelompok II dan pengelompokan anggota sampel dilakukan secara acak atau random.

Populasi dalam penelitian ini adalah siswa di SMK NU Ungaran yang berjumlah 222 orang Teknik pengambilan sampel yang digunakan dalam penelitian ini adalah proportional random sampling. Menurut Juliadai dkk (2014), proportional random sampling merupakan teknik penentuan populasi yang terbagi menjadi beberapa kelompok, namun tidak ada strata/jenjang atau tidak ada satu kelomok yang lebih tinggi dari kelompok lainnya.

Variabel independen pendidikan kesehatan menggunakan media leaflet dan media audio visual pada remaja putri dan variabel dependen pengetahuan pemeriksaan payudara sendiri (SADARI).

Dalam penelitian ini, instrumen yang digunakan adalah lembar kuesioner yang terdiri dari 20 pertanyaan dengan skor jawaban : $2=$ Benar , $1=$ Mendekati Benar , $0=$ Salah. Jumlah skor minimal 0 dan skor maksimal 40. Kuesioner yang digunakan untuk mengetahui pengetahuan remaja adalah kuesioner yang telah dilakukan oleh Lormita Purba yang telah di uji validitas di Universitas HKBP Nomense Pematang Siantar tahun 2013.

Bahan yang digunakan dalam penelitian ini adalah media leaflet dan media audio visual. Peneliti diawali dari mengidentifikasi responden yang pengetahuannya kurang tentang SADARI dengan menggunakan kuesioner. Kemudian peneliti memberikan lembar inform consent kepada responden sebagai persetujuan untuk menjadi sampel dalam penelitian ini. Setelah itu peneliti melakukan pretest dengan menggunakan lembar kuesioner untuk mengukur pengetahuan dengan menggunakan kuesioner.

Analisis data menggunakan uji normalitas data dilakukan dengan menggunakan uji shapiro wilk. Uji ini bertujuan untuk mengetahui distribusi data mempunyai distribusi normal ataupun tidak dengan ketentuan nilai keyakinan yang dipakai adalah 0,95 dan nilai kemaknaan $\alpha=0,05$ (Arikunto,2011).

Untuk mengetahui keefektifan pendidikan kesehatan pada masingmasing media digunakan uji $t$ test dependent jika data yang berdistribusi normal dan untuk mengetahui perbedaan efektivitas dari media leaflet dan audio visual dengan uji $t$ test independent.

\section{HASIL}

Hasil pengumpulan data pada remaja putri dapat diketahui bahwa dari 34 responden kelompok audiovisual, lebih banyak didominasi oleh remaja putri yang berumur 17 tahun, sejumlah 18 remaja $(52,9 \%)$. Sedangkan dari 35 responden kelompok leaflet, sebagian besar juga berumur 17 tahun, yaitu sejumlah 22 remaja $(62,9 \%)$.

Dari 34 responden kelompok Audio Visual, sebelum diberikan pendidikan kesehatan menggunakan audio visual, rata-rata skor pengetahuan remaja putri tentang Pemeriksaan Payudara Sendiri (SADARI) sebesar 27,12 dengan standar deviasi 3,88. Skor paling rendah sebesar 18 dan paling tinggi sebesar 33. Kemudian sesudah diberikan pendidikan kesehatan menggunakan audio visual, rata-rata skor pengetahuan remaja putri tentang Pemeriksaan Payudara Sendiri (SADARI) berubah menjadi 33,59 dengan standar deviasi 2,68. Skor paling rendah menjadi 26 dan paling tinggi menjadi 38.

Dari 35 responden kelompok leaflet, sebelum diberikan pendidikan 
kesehatan menggunakan leaflet, ratarata skor pengetahuan remaja putri tentang Pemeriksaan Payudara Sendiri (SADARI) sebesar 27,26 dengan standar deviasi 4,29. Skor paling rendah sebesar 16 dan paling tinggi sebesar 35 . Kemudian sesudah diberikan pendidikan kesehatan menggunakan leaflet, rata-rata skor pengetahuan remaja putri tentang Pemeriksaan Payudara Sendiri (SADARI) berubah menjadi 31,71 dengan standar deviasi 3,18 . Skor paling rendah menjadi 24 dan paling tinggi menjadi 37.

Tabel 1. Uji normalitas data

\begin{tabular}{llllll}
\hline Variabel & \multicolumn{2}{l}{ Perlakuan Kelompok } & n & p-value & Kesimpulan \\
\hline Pengetahuan & Pretest & Audiovisual & $\mathbf{3 4}$ & $\mathbf{0 , 0 5 7}$ & Normal \\
& & Leaflet & $\mathbf{3 5}$ & $\mathbf{0 , 5 0 4}$ & Normal \\
\hline \multirow{3}{*}{ Posttest } & Audiovisual & $\mathbf{3 4}$ & $\mathbf{0 , 1 2 3}$ & Normal \\
& & Leaflet & $\mathbf{3 5}$ & $\mathbf{0 , 2 0 2}$ & Normal \\
\hline
\end{tabular}

Uji normalitas menggunakan Saphiro Wilk sebagaimana disajikan pada tabel 4.4 didapatkan p-value untuk variabel pengetahuan pretest kelompok audiovisual dan leaflet masing-masing sebesar 0,057 dan 0,504> $\alpha(0,05)$. Kemudian, p-value untuk variabel pengetahuan posttest kelompok audio visual dan leaflet masing-masing sebesar 0,123 dan $0,202>\alpha(0,05)$. Oleh karena keempat p-value tersebut lebih besar dari $\alpha(0,05)$, sehingga disimpulkan bahwa semua data dapat dinyatakan berdistribusi normal. Karena data yang diperoleh berdisribusi normal maka pengujian dilakukan menggunakan uji $\mathrm{t}$ independen dan uji $\mathrm{t}$ dependen.

Tabel 2. Uji homogenitas Pengetahuan Remaja Putri Sebelum Perlakuan antara Kelompok Audio Visual dan Kelompok Leaflet

\begin{tabular}{llcllll}
\hline Variabel & Kelompok & N & Mean & SD & t & p-value \\
\hline Pengetahuan & Audio Visual & $\mathbf{3 4}$ & $\mathbf{2 7 , 1 2}$ & $\mathbf{3 , 8 8}$ & $\mathbf{- 0 , 1 4 1}$ & $\mathbf{0 , 8 8 8}$ \\
& Leaflet & 35 & $\mathbf{2 7 , 2 6}$ & $\mathbf{4 , 2 9}$ & & \\
\hline
\end{tabular}

Hasil uji ini dikatakan setara atau homogen apabila tidak ada perbedaan secara bermakna antara pengetahuan responden sebelum perlakuan antara kelompok audio visual dan kelompok leaflet $(\mathrm{p}>0,05)$, begitu juga sebaliknya, didapatkan nilai $t$ hitung -0,141 dengan p-value 0,888 . Karena p-value $0,888>\alpha(0,05)$, maka dapat disimpulkan bahwa tidak ada perbedaan yang signifikan pengetahuan remaja putri tentang SADARI sebelum perlakuan antara kelompok audio visual dan kelompok leaflet di SMK NU Ungaran. Ini juga menunjukkan bahwa kedua kelompok memiliki pengetahuan yang setara sebelum perlakuan atau dapat dinyatakan homogen sebelum penelitian. 
Tabel 3. Perbedaan Pengetahuan Remaja Putri tentang Pemeriksaan Payudara Sendiri (SADARI) sebelum dan sesudah diberikan pendidikan kesehatan dengan menggunakan media audio visual di SMK NU Ungaran

\begin{tabular}{lcccccc}
\hline Variabel & Perlakuan & n & Mean & SD & T & p-value \\
\hline Pengetahuan & Sebelum & $\mathbf{3 4}$ & $\mathbf{2 7 , 1 2}$ & $\mathbf{3 , 8 8}$ & $\mathbf{- 7 , 9 1 2}$ & $\mathbf{0 , 0}$ \\
& Sesudah & $\mathbf{3 4}$ & $\mathbf{3 3 , 5 9}$ & $\mathbf{2 , 6 8}$ & & $\mathbf{0 0}$
\end{tabular}

Diketahui bahwa pada kelompok audio visual, sebelum diberikan pendidikan kesehatan menggunakan media audio visual, rata-rata skor pengetahuan remaja putri tentang SADARI sebesar 27,12. Kemudian sesudah diberikan pendidikan kesehatan menggunakan media audio visual meningkat menjadi 33,59. Berdasarkan uji t dependen, didapatkan nilai t hitung sebesar -7,912 dengan p-value sebesar 0,000 . Terlihat bahwa p-value $0,000<\alpha$ $(0,05)$, ini menunjukkan bahwa ada perbedaan secara signifikan pengetahuan remaja putri tentang pemeriksaan payudara sendiri (SADARI) sebelum dan sesudah diberikan pendidikan kesehatan dengan menggunakan media audio visual di SMK NU Ungaran.

Tabel 4. Perbedaan Pengetahuan Remaja Putri tentang Pemeriksaan Payudara Sendiri (SADARI) sebelum dan sesudah diberikan pendidikan kesehatan dengan menggunakan Leaflet di SMK NU Ungaran

\begin{tabular}{rrrrrrr}
\hline Variabel & Perlakuan n & Mean SD & T & $\begin{array}{l}\text { p- } \\
\text { value }\end{array}$ \\
\hline Pengetahuan Sebelum & 35 & 27,26 & 4,29 & - & $\mathbf{0 , 0 0 0}$ \\
Sesudah & 35 & 31,71 & 3,18 & 8,751 &
\end{tabular}

Diketahui bahwa pada kelompok leaflet, sebelum diberikan pendidikan kesehatan menggunakan leaflet, ratarata skor pengetahuan remaja putri tentang SADARI sebesar 27,26. Kemudian sesudah diberikan pendidikan kesehatan menggunakan leaflet meningkat menjadi 31,71. Berdasarkan uji t dependen, didapatkan nilai t hitung sebesar $-8,751$ dengan $\mathrm{p}$ - value sebesar 0,000 . Terlihat bahwa $\mathrm{p}$ value $0,000<\alpha(0,05)$, ini menunjukkan bahwa ada perbedaan secara signifikan pengetahuan remaja putri tentang pemeriksaan payudara sendiri (SADARI) sebelum dan sesudah diberikan pendidikan kesehatan dengan menggunakan leaflet di SMK NU Ungaran. 
Tabel 5. Perbedaan Efektivitas Pendidikan Kesehatan Menggunakan Audio Visual dan Leaflet terhadap Pengetahuan Remaja Putri tentang SADARI

\begin{tabular}{lllllll}
\hline Variabel & $\begin{array}{l}\text { Kelompok } \\
\text { Perlakuan }\end{array}$ & N & Mean & SD & t & p-value \\
\hline Selisih Pengetahuan & Audio Visual & $\mathbf{3 4}$ & $\mathbf{6 , 4 7}$ & $\mathbf{4 , 7 7}$ & $\mathbf{2 , 0 9 0}$ & $\mathbf{0 , 0 4 0}$ \\
& Leaflet & 35 & $\mathbf{4 , 4 6}$ & $\mathbf{3 , 0 1}$ & & \\
& & & & &
\end{tabular}

Rata-rata peningkatan skor pengetahuan remaja putri tentang SADARI yang diberikan pendidikan kesehatan menggunakan media audio visual sebesar 6,47. Ini lebih tinggi dibandingkan sesudah diberikan pendidikan kesehatan menggunakan leaflet, dengan rata-rata peningkatan skor sebesar 4,46.

Berdasarkan uji $\mathrm{t}$ independen, didapatkan nilai t hitung sebesar 2,090 dengan $\mathrm{p}$-value 0,040 . Karena $\mathrm{p}$-value $0,040<\alpha(0,05)$, maka dapat disimpulkan bahwa ada perbedaan yang signifikan efektivitas pendidikan kesehatan menggunakan audio visual dan leaflet terhadap Pengetahuan Remaja Putri tentang pemeriksaan payudara sendiri (SADARI) di SMK NU Ungaran. Penggunaan media audio visual memiliki pengaruh yang lebih tinggi terhadap pengetahuan remaja putri dengan kenaikan skor rata-rata sebesar 6,47 dibandingkan penggunaan leaflet yang hanya sebesar 4,46.

\section{PEMBAHASAN}

Hasil penelitian ini sejalan dengan penelitian yang dilakukan oleh (Ambarwati, Sugita, \& Susilowati, 2014) dengan judul Hubungan Pengetahuan SADARI Dengan Minat Deteksi Dini Kanker Payudara Pada Remaja Putri Di SMA N 1 Karang Dowo Klaten berdasarkan hasil penelitiannya didapatkan bahwa tingkat pengetahuan terbanyak berada dalam kategori sedang sebanyak 80 responden $(73,4 \%)$, sedangkan tingkat pengetahuan terendah berada pada kategori buruk sebanyak 12 responden $(11,1 \%)$ dari 109 responden. Rendahnya tingkat pengetahuan masyarakat mengenai pentingnya pemeriksaan SADARI disebabkan oleh kurangnya informasi serta tingkat kewaspadaan masyarakat terhadap kanker payudara.

Pengetahuan adalah kesan dalam pikiran manusia sebagai hasil penggunaan panca inderanya. Pengetahuan adalah segala sesuatu apa yang diketahui berdasarkan pengalaman yang didapatkan oleh setiap manusia (Olfah et al., 2013). Pengetahuan perempuan tentang risiko dan manfaat dari deteksi dini kanker payudara berpengaruh positif terhadap keyakinan mereka tentang kesehatan, sikap, dan perilaku, sehingga perawatan kesehatan professional dapat mengembangkan program kesehatan payudara yang efektif (Erbil \& Bolukbas, 2012).

Hasil penelitian ini sejalan dengan penelitian yang dilakukan oleh (Tri Viviawati, 2014) dengan judul pengaruh pendidikan kesehatan tentang pemeriksaan SADARI sebagai deteksi dini kanker payudara terhadap pengetahuan dan sikap remaja putri di SMK N 1 Karanganyar berdasarkan hasil penelitiannya didapatkan hubungan yang signifikan antara pengetahuan remaja putri dengan pelaksanaan pemeriksaan SADARI dengan pengetahuan cukup sebesar 26 responden $(84 \%)$ dan dalam kategori kurang yaitu sebesar 5 responden (16\%) dari 31 responden dimana responden yang berpengetahuan cukup sebagian 
besar kurang mengetahui manfaat dan cara pemeriksaan SADARI.

Hasil penelitian (Irma, 2008) tentang SADARI di SMA YP Swasta Medan. Dari 96 responden yang diteliti mayoritas yang berpengetahuan kurang sebanyak 60 orang (62,5\%), pengetahuan cukup sebanyak 35 orang $(36,5 \%)$, sedangkan minoritas yang berpengetahuan baik sebanyak 1 orang (1,0\%) (Varney, 2007). Pada pendidikan kesehatan tentang SADARI, diharapkan dapat meningkatkan pemahaman serta perubahan pengetahuan, sikap dan perilaku remaja. Serta dengan media pendidikan tersebut dapat berpengaruh secara efektif. Sehingga remaja dapat melakukan tindakan yang terbaik kaitannya dengan SADARI untuk deteksi dini kanker payudara (Machfoedz, 2008; Ghartey, 2016).

Media promosi kesehatan adalah semua sarana atau upaya untuk menampilkan pesan atau informasi yang ingin disampaikan oleh komunikator. Promosi kesehatan tidak lepas dari media karena melalui media, pesanpesan yang disampaikan dapat lebih menarik dan dipahami, sehingga sasaran dapat lebih mempelajari pesan tersebut sehingga sampai memutuskan untuk mengadopsi perilaku yang positif. Banyak media promosi kesehatan yang dapat digunakan, salah satunya audio visual. Media audio visual merupakan jenis media yang selain mengandung unsur suara juga mengandung unsur gambaran yang dapat dilihat, seperti rekaman vidio, slide suara dan lain sebagainya( Notoatmodji, 2007). Kemampuan media audio visual ini dianggap lebih baik dan menarik, sebab mengandung kedua unsur, yaitu di dengar dan dilihat.

Melalui media video, mahasiswa dapat diajak melihat pergerakan sel kanker, atau mendengar penjelasan dari narasumber secara langsung mengenai pengetahuan tentang kanker payudara. Efek gambar yang bergerak tentu saja akan memberikan pengalaman belajar yang lebih kaya dibanding hanya melalui gambar diam seperti pada leaflet. Dengan adanya media video dalam promosi kesehatan, maka mahasiswa akan cepat memahami tentang kanker payudara. Selain itu, media video juga bisa membuat mahasiswa fokus dengan materi promosi karena adanya gerakan yang membuat mata menjadi fokus untuk melihat ke arah gerakan dibanding hanya gambar diam yang cenderung monoton.

Berdasarkan pembahasan diatas peneliti berasumsi bahwa dengan adanya media pembelajaran yang didukung dengan media yang menyajikan tulisan serta gambar yang lebih detail sehingga dapat diamati dengan jelas maka akan membangkitkan semangat remaja untuk dapat memahami dan mencerna materi yang diberikan oleh pengajar sehingga pengetahuan siswa akan meningkat tentang SADARI.

Hasil penelitian ini sesuai dengan penelitian (Sorea, 2015) dengan judul efektifitas promosi kesehatan melalui audio visual tentang pemeriksaan payudara sendiri (SADARI) terhadap peningkatan pengetahuan remaja putri di SMAN 2 Pekanbaru. Hasil penelitian didapatkan pendidikan kesehatan menggunakan media audiovisual efektif terhadap peningkatan pengetahuan tentang kemampuan merawat bayi baru lahir dengan nilai $\mathrm{p}$ value 0,000 pada $\alpha<$ 0,05 .

Pengetahuan mengenai SADARI sebagai deteksi dini adanya kanker payudara merupakan faktor penting terbentuknya perilaku SADARI. Salah satu cara untuk mendapatkan pengetahuan tentang SADARI adalah dengan leaflet SADARI. Leaflet adalah 
bentuk penyampaian infomasi atau pesan - pesan kesehatan melalui lembaran yang dilipat, isinya berupa kalimat ataupun gambar atau kombinasi. Leaflet memiliki kelebihan sasaran dapat menyesuaikan dan belajar mandiri, dapat memberikan informasi secara detail , mudah dibuat, diperbanyak dan direvisi.

Leaflet merupakan salah satu alat peraga yang disusun berdasarkan prinsip bahwa pengetahuan manusia diterima atau ditangkap melalui panca indra. Leaflet yang baik adalah menggunakan bahasa yang sederhana, mudah dimengerti oleh pembacanya, judul yang digunakan menarik untuk dibaca serta dikombinasikan antara tulisan dan gambar, serta materinya sesuai dengan target yang dituju. Leaflet dapat tersebar luas dan merupakan salah satu cara yang berguna untuk menyampaikan informasi kepada para wanita dan keluarganya atau mendukung informasi yang mereka terima ( Yulianti D, 2011).

Hasil penelitian didapatkan bahwa keterampilan deteksi dini kanker payudara ( SADARI) pada mahasiswa yang diberi promosi kesehatan menggunakan audio lebih efektif dibandingkan dengan yang menggunakan leaflet. Menurut asumsi peneliti media leaflet memiliki beberapa kekurangan jika dibandingkan dengan media video, salah satunya adalah media leaflet hanya memuat gambar sedangkan pada video memuat gambar bergerak. Perbedaan ini bisa memberikan informasi yang berbeda pula bagi sebagian orang terlebih pada bagian pemaparan langkah-langkah deteksi dini atau SADARI. Pada gambar di leaflet, hanya ditunjukkan langkah dengan panduan berupa gambar yang terkadang sulit untuk dipahami audiens. Namun hal ini menjadi mudah dipahami jika menggunakan media video karena dalam video dicontohkan secara langsung sehingga audiens langsung mengerti.

\section{SIMPULAN}

Penggunaan media audio visual lebih efektif dan lebih baik dalam meningkatkan pengetahuan pada remaja putri di SMK NU Ungaran.

\section{SARAN}

Hendaknya pihak sekolah dapat melakukan penelitian dengan menggunakan media audio visual dengan tampilan yang berbeda seperti 3D atau gambar animasi yang dapat menarik pada saat melakukan pendidikan kesehatan agar responden tidak monoton dan membosankan sehingga dapat meningkatkan pendidikan kesehatan pada remaja putri dalam mencegah kanker payudara dan dapat menambahkan diadakan kuis agar menarik para audiens untuk mengikuti.

\section{KEPUSTAKAAN}

Alini , Indrawati. (2018). Efektifitas Promosi Kesehatan Melalui Audio Visual Dan Leaflet Tentang Sadari (Pemeriksaan Payudara Sendiri) Terhadap Peningkatan Pengetahuan Remaja Putritentang Sadari Di SMAN 1 Kampartahun 2018. Jurnal ners volume 2 nomor 2 tahun 2018 halaman $1-9$. Http:// journal.universitaspahlawan.ac.i d/index.php/ners.

Ani Nur Fauziah, dkk. (2017). Pengaruh Leaflet Terhadap Peningkatan Pengetahuan Tentang Pemeriksaan Payudara Sendiri (SADARI). Gaster Vol. XV No.2 (2017).

Aronida Mutia Yuslikhah dkk. (2019). The Effectiveness of Health Education Method on Early Detection Carcinoma Mammae 
in Teenage Girls At Madrasah Aliyah in Mijen Sub-District. Public Health Perspectives Journal 4 (2) (2019) 109 - 115. http://journal.unnes.ac.id/sju/ind ex.php/phpj.

Departemen kesehatan RI. (2014). Pusat Dana Informasi. Profil Kesehatan Kabupaten Semarang. $\quad$ www.Depkes. Go.Id/Profil/PROFIL_KAB.../3 322_Jateng_Kab_Semarang.

Diakses Pada Tanggal 10 Febuari 2019.

Eka Afrima Sari, dkk. (2016). Motivasi Mahasiswi Keperawatan Dalam Pemeriksaan Payudara Sendiri Sebagai Deteksi Dini Kanker Payudara. Jurnal Ilmu Keperawatan,Vol.IV No.1 (2016).

Hafriani. (2016). Pengaruh Penyuluhan Kesehatan Menggunakan Media Video Dan Leafleat Terhadap Pengetahuan Dan Sikap Siswi Dalam Pemeriksaan Payudara Sendiri Di Sman 1 Simpang Empat Dan SMAN 1 Kisaran Tahun 2016. Issn : 2460-4356.

Infodatin (PUSAT DATA DAN INFORMASI KEMENTERIAN
KESEHATAN RI). (2015). Stop

Kanker. Diakses dari www.depkes.go.id/resources/do wnload/pusdatin/infodatin/infod atinkanker.pdf (diakses pada tanggal 20 November 2018).

Kemenkes RI. (2015). Profil Kesehatan Indonesia tahun 2015. Jakarta.

Kemenkes RI. (2016). Profil Kesehatan Indonesia tahun 2016. Jakarta.

Kemenkes RI. (2018). Hasil Utama Riskesdas 2018. Jakarta.

Netti Herawati, dkk. (2017). Studi Perbandingan Promosi Kesehatan Antara Leaflet Dengan Video Terhadap Pengetahuan Tentang Kankerpayudaa Dan Keterampilan Deteksi Dini Kanker Payudara (SADARI) Pada Remaja Putri Di Jurusan Kebidanan Poltekkes Jambi Tahun 2016. Tekno-Pedagogi Vol.77 No.2 (2017) :1-14.

Notoatmodjo. (2014). Promosi Kesehatan dan Perilaku Kesehatan. Jakarta: Rineka Cipta. 